\title{
Theoretical and experimental investigation of effect of salinity and asphaltene on IFT of brine and live oil samples
}

\author{
Aboozar Soleymanzadeh ${ }^{1} \cdot$ Ahmadreza Rahmati $^{2} \cdot$ Mohammad Yousefi $^{3} \cdot$ Babak Roshani $^{2}$
}

Received: 23 May 2020 / Accepted: 8 October 2020 / Published online: 20 October 2020

(c) The Author(s) 2020

\begin{abstract}
Several factors influence the IFT of oil and formation water. These factors are rooted in the complex composition of oil, presence of different salts in water, water salinity, temperature, and pressure of reservoir. In the first part of this paper, effect of salinity on IFT between brine and an Iranian live oil sample has been studied experimentally. It is observed that IFT increases almost linearly with brine concentration. Also, linear increasing behavior of IFT with respect to pressure is obviously seen. Then, using thermodynamic properties such as surface excess concentration, chemical potential, chemical activity, and activity coefficient, results were analyzed and observed effect of salinity and pressure were justified thermodynamically. In the second part, the effect of asphaltene on IFT reduction has been studied. In previous works, the investigators extracted resin and asphaltene and then examined their effects on IFT in the absence of other fractions of oil phase. We believe that all fractions play a role in this phenomenon so, in this paper, the effect of natural surfactants of oil phase on IFT has been investigated in presence of all fractions of oil. Hence, SARA test was performed on all samples. Then, IFT between oil samples and brine were measured using captive drop instrument at $25^{\circ} \mathrm{C}$ and $3000 \mathrm{psia}$. Results showed that neither asphaltene content nor asphaltene/resin ratio is a good indicator for effect of asphaltene on IFT, whereas colloidal instability index could be a useful tool to predict asphaltene effect on IFT.
\end{abstract}

Keywords Interfacial tension $\cdot$ Asphaltene $\cdot$ Salinity $\cdot$ Chemical activity

\section{Introduction}

Surface tension or interfacial tension (IFT, denoted by $\sigma$ ) is a parameter that describes behavior of interface between two immiscible fluids. Generally, surface tension and interfacial tension are applied for interfacial forces between gas/liquid

Aboozar Soleymanzadeh

a.soleymanzadeh@put.ac.ir

Ahmadreza Rahmati

ar_rahmati@kashanu.ac.ir

Mohammad Yousefi

myousefi@ualberta.ca

Babak Roshani

bab_roshani@yahoo.com

1 Department of Petroleum Engineering, Ahvaz Faculty of Petroleum, Petroleum University of Technology (PUT), Ahvaz, Iran

2 Department of Mechanical Engineering, University of Kashan, Kashan, Iran

3 University of Alberta, Edmonton, Canada and liquid/liquid interfaces, respectively. Attraction forces for two immiscible fluids in their bulk volumes and at their surface are presented in Fig. 1 (McCain 1990; Dandekar 2013; Barati-Harooni et al. 2016; Meybodi et al. 2016).

Sometimes IFT is defined based on change in Helmholtz and Gibbs energies when area of interface changes by $\partial A$ (Li 2013). Equations 1 and 2 show these definitions. In these equations, $F$ and $G$ are Helmholtz and Gibbs energies.

$\sigma=\left(\frac{\partial F}{\partial A}\right)_{p, V, n_{i}}$

$\sigma=\left(\frac{\partial G}{\partial A}\right)_{T, P, n_{i}}$

Several variables influence the IFT of oil and formation water. These factors are rooted in the complex composition of oil, presence of different salts in water and wide variation of formation water salinities, temperature and pressure condition of reservoir. Hoeiland et al. (2001) concluded that the value of IFT reduces only at high $\mathrm{pH}$ condition when the crude oil sample contains acidic components. Bai et al. 


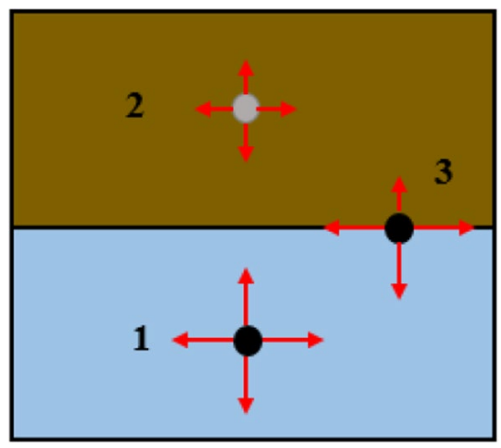

Fig. 1 Attraction forces for two immiscible fluids

(2010) showed that when $\mathrm{pH}>10$, there is a drastic decrease in IFT with increase in $\mathrm{pH}$. At basic condition, the acidic species in the polar components create naphthenates, which can interact with petroleum sulfonate. The synergetic influence of petroleum sulfonate and the active species of crude oil sample can create a remarkable reduction in the IFT value. They stated that the sample with higher acid number creates more naphthenates, resulting in the lower values of IFT. Cratin (1993) and Kelesoglu et al. (2011) reported that the reduction of IFT between brine and oil with increasing $\mathrm{pH}$ value is related to the dissociation of acidic constituents. Buckley and Fan (2007) investigated effect of various variables such as $\mathrm{pH}$ of brine, fluid densities, fluid viscosities, asphaltene content of oil and acid and base numbers. They used 42 oil samples and different aqueous solutions including double-distilled water (DDW), $0.1 \mathrm{M} \mathrm{NaCl}$, and synthetic seawater. The asphaltene content of their oil samples varied from 0.05 to $8.75 \mathrm{wt} \%$, acid numbers changed from about $0.01 \mathrm{mg} \mathrm{KOH} / \mathrm{g}$ oil to $3.92 \mathrm{mg} \mathrm{KOH} / \mathrm{g}$ oil, and base numbers ranged from 0.11 to $5.19 \mathrm{mg} \mathrm{KOH} / \mathrm{g}$ oil. Buckley and Fan reported that the key oil properties which correlate with IFT between oil and $\mathrm{pH}$-adjusted distilled water and $0.1 \mathrm{M} \mathrm{NaCl}$ solutions are the asphaltene content, acid number, base number and viscosity. They concluded that IFT reduces with increasing acid number and increases with increasing viscosity. Furthermore, they stated that IFT increases with increasing base number. Acid number is effective in the very basic condition, i.e., for $\mathrm{pH}>10$. Ultralow IFT values are obtained for acid numbers greater than $0.1 \mathrm{mg} \mathrm{KOH} / \mathrm{g}$ oil. Additionally, Buckley and Fan found that the base number influences IFT at weakly basic oil condition.

Alves et al. (2014) studied the effect of the salinity of the brine phase on the interfacial properties of the brine and crude oil. Their results revealed that increasing the salt concentration enhances the total interfacial elasticity and elastic and viscous modulus. Furthermore, they concluded that the presence of salt in aqueous phase increase the rigidity of the interfacial film. Also, addition of salt into the aqueous phase improves the interfacial activity of the surfactants that enhances the elasticity and compressibility of the interface.

Lashkarbolooki et al. (2016) categorized effect of oil and formation water compositions on IFT in three groups: (1) existence of asphaltene and resins in oil composition as natural surfactants, (2) salinity of formation water, and (3) the presence of different types of salts.

Lashkarbolooki and Ayatollahi (2018) examined the effect of acid number, asphaltene and resin content of the oil on the IFT between oils and brine solutions with different $\mathrm{pH}$ values and salt concentrations. They reported that acid number is not sufficient to describe the interfacial behavior of different oil samples. Lashkarbolooki and Ayatollahi stated that the presence of heteroatoms such as those containing sulfur, nitrogen, and oxygen in the asphaltene structure and the $\mathrm{pH}$ brine phase significantly affect the value of IFT. Moreover, the changes of IFT with respect to $\mathrm{pH}$ are similar for both seawater and deionized water.

Sayed et al. (2019) measured the IFT value between decane containing a homologous series of carboxylic acids and brine including different anions and cations. Their experimental results showed that salinity does not greatly influence the value of IFT between pure dacane and brine solutions. Moreover, they reported that addition of carboxylic acids into the decane phase considerably decreases the IFT between dacane and brine. But, Sayed et al. did not observed significant influence of the carbon chain length. They concluded that there are no clear trends between the IFT values when the cation changes from $\mathrm{Na}^{+}$ to $\mathrm{K}^{+}$and $\mathrm{Ca}^{2+}$ with the anion being kept unvaried as $\mathrm{Cl}^{-}$. In contrast, they indicated that variation of the anion from chloride to carbonate greatly reduces the IFT. In other words, presence of the carbonate anion in the brine phase increases the $\mathrm{pH}$ value and therefore a transformation of the constituent acids from neutral to their anionic form.

Drexler et al. (2020) studied the effect of $\mathrm{CO}_{2}$ content of oil on the IFT using measurement of IFT between a high salinity water and an oil sample with a high value of base number and non-negligible acid number. Their results showed that dissolution of $\mathrm{CO}_{2}$ leads to $56 \%$ increase in IFT which indicates that despite the high value of base number of the oil sample, basic groups have insignificant surface activity. Moreover, Drexler et al. investigated the effect of $\mathrm{pH}$ on IFT and concluded that the maximum value of IFT was obtained at strongly acidic condition, but constant values of IFT values occurred at neutral and basic conditions.

The main affecting parameters on recovery of trapped oil after primary and secondary production are wettability, IFT, and viscosity. These parameters are included in a dimensionless number as capillary number, $N_{c a} . N_{c a}$ is defined as Eq. 3: 
$N_{\mathrm{ca}}=\frac{\mu V}{\sigma \cos \theta}$

where $\mu$ is viscosity of injected fluid, $V$ is velocity and $\theta$ is contact angle. For an ideal enhanced oil recovery (EOR) process, $N_{c a}$ should be maximized. Decrease in IFT increases value of capillary number. So, one of the main mechanisms in most of EOR processes such as low salinity water injection, smart water injection, and surfactant injection is reduction of IFT. In the mentioned EOR operations, salinity of injected water has great influence on the performance of that operation (Barati-Harooni et al. 2016).

As noted in this section, most of the experimental studies on the IFT between oil and brine have been conducted on the dead oil sample or pure hydrocarbon such as decane. Also, review of these studies reveals that the effect of presence of saturate and aromatic fractions of the oil samples has not been considered and less attention has been given to the thermodynamics of the effect of pressure and concentration on IFT. Therefore, in this work, the effect of salinity (different concentrations of $\mathrm{NaCl}$ in distilled water) and presence of saturate and aromatic fractions of oil sample on IFT between brine and a live oil sample (sample A) from an Iranian reservoir were studied experimentally. Experiments were conducted at $25{ }^{\circ} \mathrm{C}$ and in the concentration range of $50,000-260,000 \mathrm{ppm} \mathrm{NaCl}$ in distilled water and pressure 2500 psi up to 4000 psi. Furthermore, obtained results are analyzed and observed effect of salinity and pressure are justified thermodynamically.

\section{Effect of salinity on IFT between brines and oils}

Numerous studies have been done on the effect of water salinity on the IFT between hydrocarbon and brine phases. These studies showed different and in some cases opposing behaviors. Most of investigators reported an increasing trend in IFT due to increase in water salinity. Some researchers suggested contrasting behavior. Several studies about effect of water salinity on the interfacial tension between hydrocarbon and brine systems are given in Table 1 .

From Table 1, it can be concluded that behavior of a hydrocarbon/brine system generally depends on the type and amount of salts and natural surfactants in the oil/brine system.

\section{Effect of asphaltene on IFT between brines and oils}

Because of complex structure of crude oil, its elemental examination is very difficult. SARA separation is a special analysis of oil sample. In this technique crude oil is divided into four main fractions based on their solubility and polarity: saturates, aromatics, resins, and asphaltenes. Saturates are nonpolar fraction of crude oil. They have no double bonds in their structure and involve groups of straight chain and branched alkanes and cycloalkanes or naphtenes. Aromatics fraction includes benzene and its different derivatives (Ashoori 2005; Kord and Ayatollahi 2012).

Asphaltenes are the heaviest part of the crude oil which have not definite structure. They are defined as a fraction of oil that is insoluble in light normal alkanes such as n-pentane or n-heptane but soluble in aromatics solvents such as toluene and benzene (da Silva Ramos et al. 2001; Castillo et al. 2009). Resin is a fraction of oil which is not soluble in liquid propane or ethyl acetate but soluble in n-alkanes and aromatic solvents (Kord and Ayatollahi 2012; Arya et al. 2015). Polar properties of crude oil are mostly related to its asphaltene and resins content because of presence of heteroatoms (Nitrogen, Oxygen and Sulfur) in structure of these fractions (Hammami et al. 2000). When asphaltene is separated from oil, asphaltene precipitates. This phenomenon can take place in a vast domain from porous media to flowlines and separation units. Two main approaches have been suggested in the literature for precipitation of asphaltenes: solubility and colloidal approaches. In solubility model, asphaltene is considered as a fraction which has been dissolved in the oil phase as real solution. Therefore, changes in thermodynamic conditions may result in asphaltene precipitation (Yarranton et al. 2000). In colloidal model, asphaltenes are assumed as suspended particles in oil which stabilized by layers of resins on their surfaces. Stability of suspended asphaltene particles is disturbed due to desorption of resin layers from asphaltene particles. Collisions of asphaltene particles with each other on empty spots of their surfaces (which are not occupied by resins) can lead to asphaltene precipitation (Escobedo and Mansoori 1995; Yen et al. 2001; Arya et al. 2015).

Literature review on properties of asphaltenes and resins shows that they affect the interface of water and oil system and change IFT based on composition of water and oil phases. Therefore, these fractions of oil can be considered as natural surfactants. It should be noted that the mechanism of IFT change by these natural surfactants is not well understood (Lashkarbolooki et al. 2014, 2016; Lashkarbolooki and Ayatollahi 2016).

Moeini et al. (2014) used the structure of asphaltene particles to confirm their surfactant nature: asphaltenes consist of a hydrophobic part (hydrocarbon) and hydrophilic part. Hydrophilic part aligns in the water and the hydrophobic group orients into the oil phase. Therefore, asphaltene particles tend to adsorb at the interface of water and oil system which causes decrease in IFT. So, it can be expected that asphaltenes play a role such as surfactants in IFT reduction. Moeini's et al. results showed that IFT

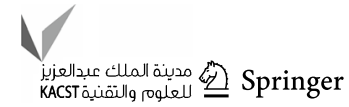




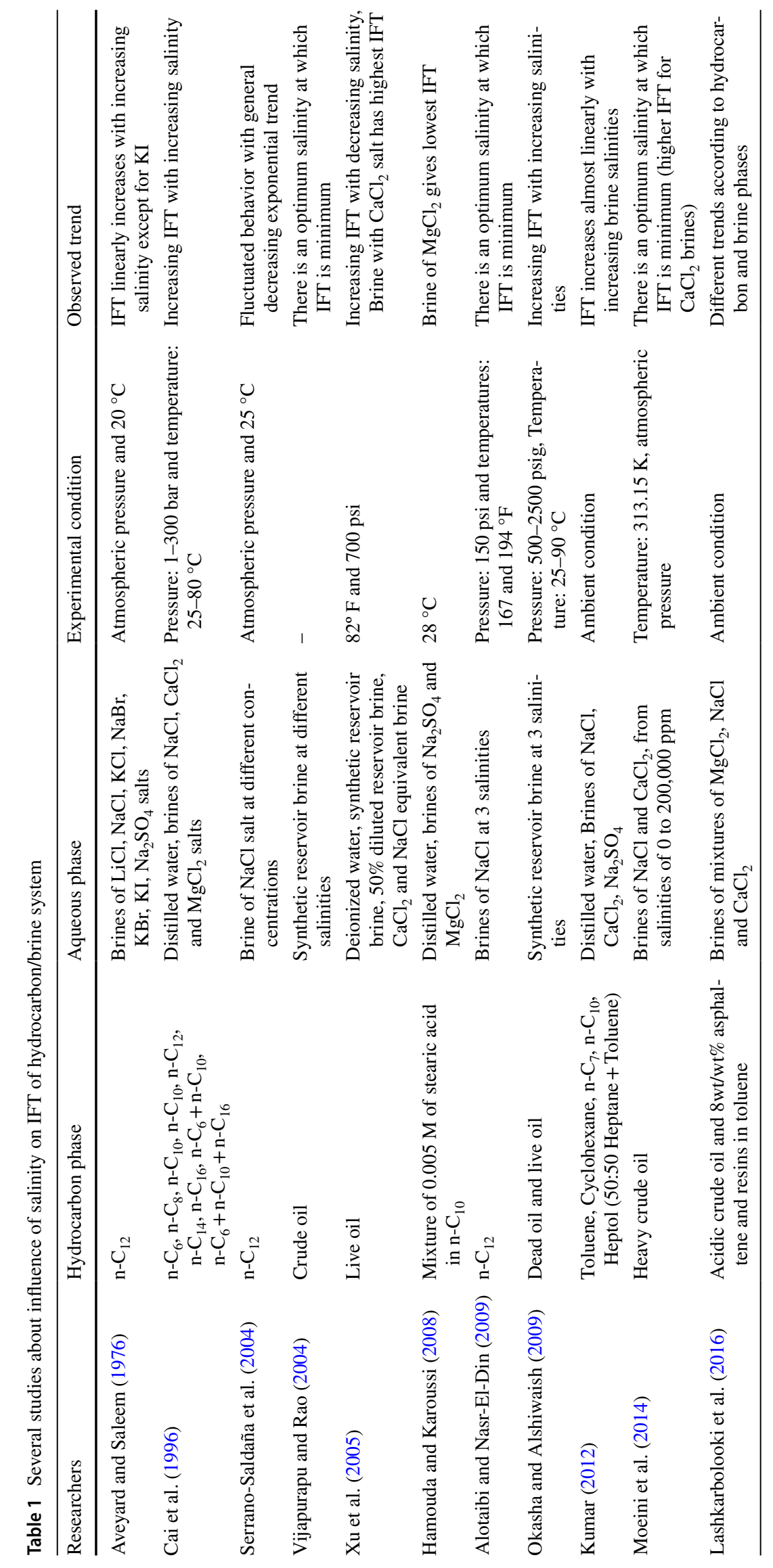


of heavy oil samples and brine is much lower than IFT of pure hydrocarbons and brine which is related to the presence of natural surfactants such as asphaltenes and resins in oil phase. Lashkarbolooki and Ayatollahi (2016) measured the IFT between solutions of $8 \mathrm{wt} / \mathrm{wt} \%$ asphaltene and resin in toluene and deionized water. They stated that lower IFT values of these solutions with respect to IFT of pure toluene and deionized water are related to surfactant roles of asphaltene and resins.

Yarranton et al. (2000) measured the IFT between solutions of Athabasca asphaltene (extracted by n-heptane and $\mathrm{n}$-pentane) in toluene and water. They found that IFT of these two systems continuously decreases with increasing asphaltene concentration. Zaki et al. (2000) prepared solutions of asphaltene in oil at different concentrations. At first, they provided a liquid sample by dissolution of $20 \mathrm{wt} \%$ of paraffin wax in decalin and then prepared different model oils by addition of asphaltene $(0.2-1 \mathrm{wt} \%)$ to this solution. Zaki et al. measured IFT between these solutions and synthetic formation brines and found that IFT decreases with increasing asphaltene concentration. da Silva Ramos et al. (2001) performed some IFT measurements between water and solutions of asphaltene (extracted from a Brazilian reservoir by $n$-pentane and $n$-heptane) in toluene. They concluded that IFT decreases as asphaltene concentration increases. They noted that precipitant type in asphaltene extraction process affects IFT reduction behavior of asphaltene. Acevedo et al. (2005) measured IFT between distilled water and solutions of asphaltene (extracted from Negro crude oil sample) in toluene. They observed reducing effect of asphaltene on IFT. Lashkarbolooki et al. (2016) investigated the effect of asphaltene and resin content of an acidic crude oil sample on IFT of sample and aqueous phase with different compositions. They extracted asphaltenes and resins fractions of their studied crude oil sample. Their results showed that the asphaltene and resin content of acidic crude oil sample were $11 \%$ and $13 \%$, respectively. Then, they prepared two solutions of $8 \mathrm{wt} / \mathrm{wt} \%$ extracted asphaltenes and resins in toluene and measured IFT of these two solutions and different aqueous phases, i.e., different brines including $\mathrm{MgCl}_{2}, \mathrm{NaCl}$, and $\mathrm{CaCl}_{2}$, to examine the sole influence of the asphaltene and resin contents on IFT. Their results revealed that none of aqueous solutions of $\mathrm{MgCl}_{2}, \mathrm{NaCl}$ and $\mathrm{CaCl}_{2}$ could motivate the resin fractions to move from the bulk of crude oil to the solution interface, and therefore the aqueous solutions reached to the high values of IFT at low concentrations. In contrast, for solutions with high concentrations of $\mathrm{MgCl}_{2}$, the likely complex ion paired containing $\mathrm{MgCl}_{2}$ and resin transferred toward the solution interface while $\mathrm{NaCl}$ and $\mathrm{CaCl}_{2}$ cannot break this molecular arrangement at the interface. Indeed, they concluded that three main affecting factors on IFT of oil/water system are presence of natural surfactants in oil phase, salt type and concentration of salts in aqueous phase.

\section{Experimental work}

\section{Materials}

Hydrocarbon phases of this work are four live oil samples, namely samples A, B, C and D from four Iranian reservoirs. These samples were prepared by recombination of separator gas and oil samples from production units. In order to provide live oil samples, oil and gas were recombined, at $25{ }^{\circ} \mathrm{C}$ and 3000 psia, by having stock tank and separator gas and stock tank liquid compositions, gas and oil formation volume factor $\left(B_{\mathrm{g}}, B_{\mathrm{o}}\right) /$ oil ratio $\left(R_{\mathrm{s}}\right)$. Stock tank oil was filtered through a Whatman filter paper No. 41 before recombination. Composition of all the studied oil samples is given in Table 2.

SARA separation test was performed for all samples. Results are shown in Table 3.

Table 2 Composition of all the studied samples

\begin{tabular}{|c|c|c|c|c|}
\hline \multirow[t]{2}{*}{ Component } & \multicolumn{4}{|l|}{$\%$ mole } \\
\hline & Sample A & Sample B & Sample C & Sample D \\
\hline $\mathrm{C} 1$ & 42.65 & 23.21 & 37.32 & 25.26 \\
\hline $\mathrm{C} 2$ & 7.88 & 9.19 & 5.49 & 7.76 \\
\hline $\mathrm{C} 3$ & 5.76 & 7.24 & 5.31 & 5.87 \\
\hline $\mathrm{i}-\mathrm{C} 4$ & 1.10 & 1.22 & 1.02 & 1.02 \\
\hline $\mathrm{n}-\mathrm{C} 4$ & 3.10 & 3.53 & 3.17 & 3.16 \\
\hline $\mathrm{i}-\mathrm{C} 5$ & 1.34 & 1.75 & 1.35 & 1.19 \\
\hline $\mathrm{n}-\mathrm{C} 5$ & 1.60 & 2.21 & 1.81 & 1.47 \\
\hline n-C6 & 2.24 & 5.06 & 2.82 & 2.97 \\
\hline $\mathrm{H} 2 \mathrm{~S}$ & 0 & 1.76 & 0.36 & 0.06 \\
\hline $\mathrm{CO}_{2}$ & 1.33 & 3.63 & 1.05 & 0.23 \\
\hline C7+ & 33 & 41.20 & 40.30 & 51.01 \\
\hline
\end{tabular}

Table 3 SARA analysis of oil samples A, B, C and D

\begin{tabular}{lllll}
\hline Oil sample & Saturates (\%) & $\begin{array}{l}\text { Aromatics } \\
(\%)\end{array}$ & Resins (\%) & $\begin{array}{l}\text { Asphaltene } \\
(\%)\end{array}$ \\
\hline A & 55.4 & 12.6 & 28.9 & 3.1 \\
B & 51.8 & 11.4 & 27 & 9.8 \\
C & 49.5 & 37.8 & 8.2 & 4.5 \\
D & 34.9 & 54.1 & 5.4 & 5.6 \\
\hline
\end{tabular}


Brine phases of this study were prepared using different concentrations of $\mathrm{NaCl}$ in distilled water. Sodium chloride $(\mathrm{NaCl}$ : purity $>99.5 \%)$ was purchased commercially. In order to prepare brine, sodium chloride was dissolved in the distilled water using a magnetic stirrer for at least $20 \mathrm{~min}$. Variation of concentrations was in the range of $50,000-260,000 \mathrm{ppm}$. Salt concentration of 180,000 ppm was used for investigation of asphaltene effect on IFT.

\section{Density measurement}

Oil and brine densities ( $\rho_{\mathrm{o}}$ and $\rho_{\mathrm{w}}$, respectively) were determined using DMA5000 of Anton Paar company at temperatures and pressures of interest. This apparatus can be applied in a temperature range of $-10{ }^{\circ} \mathrm{C}$ to $+200{ }^{\circ} \mathrm{C}$ and in a pressure interval of $0-700$ bar. This densitometer measures the oscillation period of a U-tube containing fluid sample. Table 4 shows densities (in $g / c c$ ) of oil sample A and brine at temperature $25{ }^{\circ} \mathrm{C}$ for different conditions of pressure and salinity. Also, density of four oil samples at $25^{\circ} \mathrm{C}$ and 3000 psia is given in Table 5. It is noted that densities were measured three times using the DMA5000 densitometer and their average values were presented in Tables 4 and 5. Values of standard deviation (SD) are given in Tables 4 and 5.

\section{Interfacial tension measurement}

Measurement of IFT between live oil samples and brine systems were done using pendant drop technique. Captive drop apparatus used pendant drop method for determination of interfacial tension. Numerous researchers applied this technique for measurement of IFT (Flock et al. 1986; Hjelmeland and Larrondo 1986; Badakshan and Bakes 1990; Bonfillon et al. 1994; Kashefi et al. 2016; Lashkarbolooki and Ayatollahi 2016; Najafi-Marghmaleki et al. 2016). Captive drop equipment operates in a wide range of temperature (up to $200^{\circ} \mathrm{C}$ ) and pressure (up to $11,000 \mathrm{psi}$ ). Figure 2 illustrates schematic of captive drop apparatus.

In this work, the equilibrium value of IFT was measured during experiments. Indeed, in pendant drop method, the value of IFT gradually decreases with time until reaches to a constant value as equilibrium IFT. To obtain the equilibrium value of IFT, experiments were conducted for about $45 \mathrm{~min}$. All tests were repeated three times and their average was recorded as the equilibrium value of IFT.

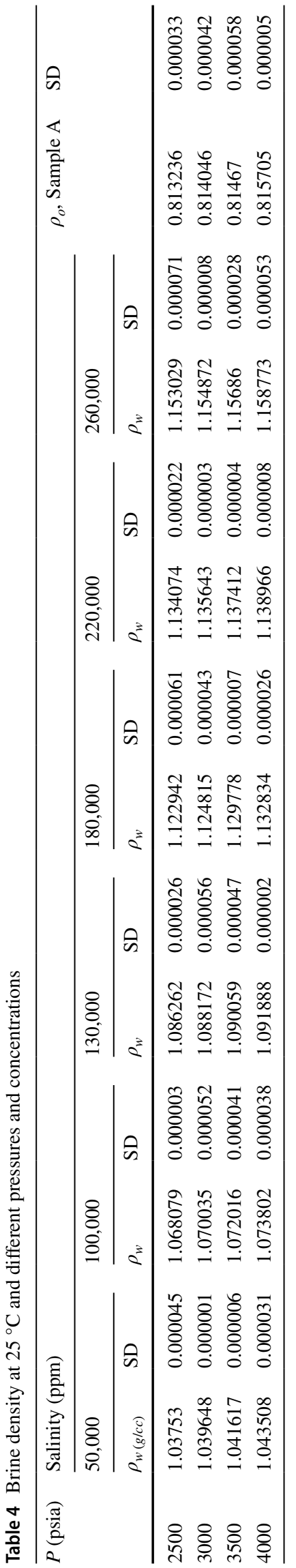




\section{Results and discussion}

\section{Effect of salinity on IFT of brine and oil sample A}

Experimental results of IFT measurement between live oil sample A and brines versus concentration of $\mathrm{NaCl}$ in distilled water is shown in Fig. 3.

Every set of data in Fig. 3 has been obtained at a constant pressure. It is clearly observed that IFT increases almost linearly with concentration of brines. Correlation coefficient $\left(R^{2}\right)$ of each fitted line verifies linear trend of data. This increasing behavior of IFT with respect to salinity confirms the most of previous studies in this topic. Later, linear trend of data will be examined from thermodynamic point of view.

To investigate the effect of pressure on the interfacial tension of oil and brines, IFT data are plotted versus pressure at constant concentrations. Linear increasing behavior of IFT with respect to pressure is obviously seen in Fig. 4 (see $R^{2}$ ). This figure reveals that IFT values with respect to pressure change in a wider range at higher concentration of brines. For example, at 50,000 ppm concentration, IFT change from $20.6 \mathrm{dyne} / \mathrm{cm}$ at $2500 \mathrm{psia}$ to 20.8 at 4000 psia. But, at $260,000 \mathrm{ppm}$ concentration, IFT change from 23.1 to $25.1 \mathrm{dyne} / \mathrm{cm}$ in the same range of pressure.
To analyze the results of Figs. 3, 4 and 5, the interface of two phases is examined from viewpoint of thermodynamics.

Gibbs derived an adsorption isotherm equation in the form of Eq. 4.

$\mathrm{d} \sigma=-\sum \Gamma_{i} \mathrm{~d} \mu_{i}$

where $\Gamma_{i}$ and $\mu_{i}$ are surface excess concentration and chemical potential of component i, respectively. $\Gamma_{i}$ is defined as the difference between concentration of component $\mathrm{i}$ in the bulk and at the interface. According to the definition of chemical potential, Eq. 4 can be written in the form of Eq. 5:

$\mathrm{d} \sigma=-R T \sum \Gamma_{i} \mathrm{~d} \ln \left(\alpha_{i}\right)$

In Eq. 5, $R$ is gas constant, $T$ is temperature and $\alpha_{i}$ presents chemical activity of component i. For a system containing two components, such as solute and solvent, $\Gamma$ for solvent is zero. So, Eq. 5 can be written in the form of Eq. 6 (Moeini et al. 2014):

$\Gamma=-\frac{\alpha}{R T} \frac{\mathrm{d} \sigma}{\mathrm{d} \alpha}$

To determine $\Gamma$, chemical activity should be calculated. Activity coefficient $(\gamma)$ is related to chemical activity based on
Table 5 Density of four oil samples at $25^{\circ} \mathrm{C}$ and 3000 psia

\begin{tabular}{lllllllll}
\hline$P$ (psia) & $\rho_{o}(\mathrm{~g} / \mathrm{cc})$ & \multicolumn{1}{l}{} \\
\cline { 2 - 9 } & Sample A & SD & Sample B & SD & Sample C & SD & Sample D & SD \\
\hline 3000 & 0.814046 & 0.000009 & 0.832227 & 0.000034 & 0.807199 & 0.000045 & 0.838905 & 0.000003 \\
\hline
\end{tabular}

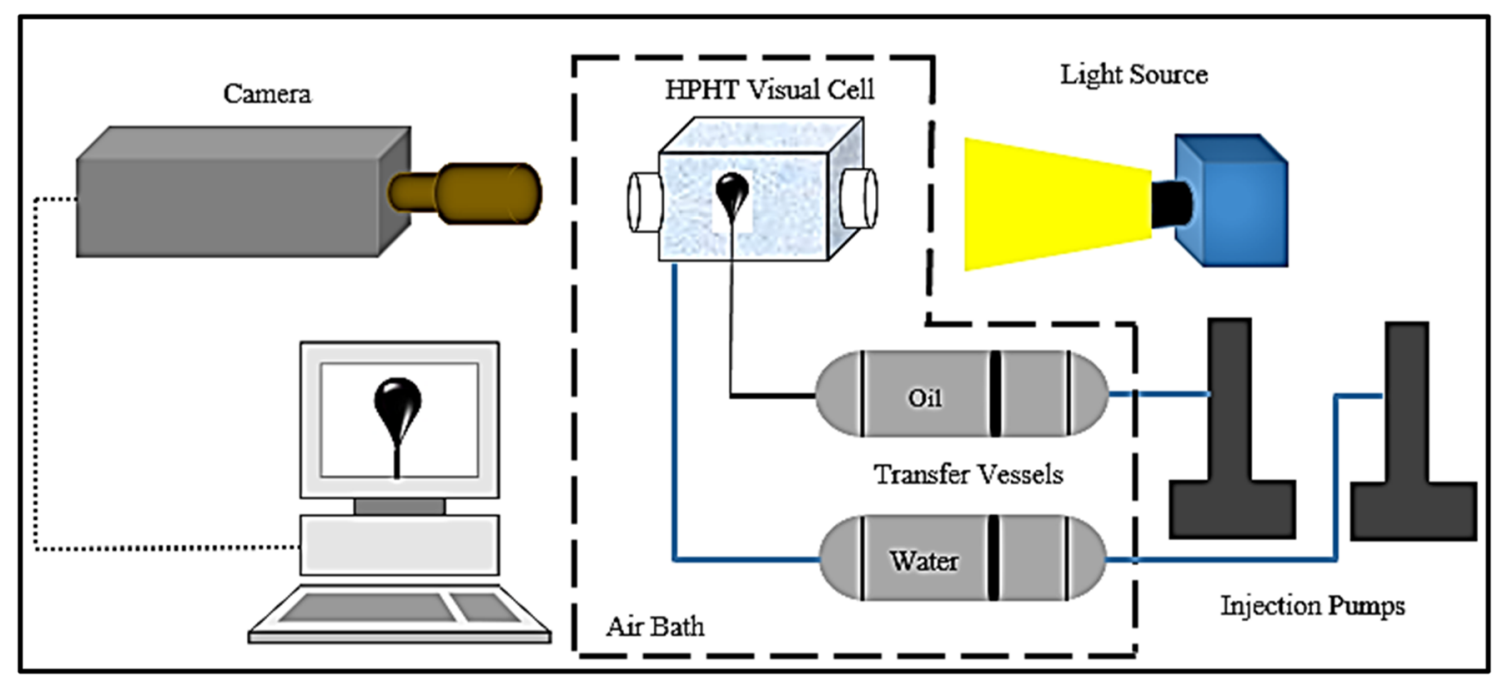

Fig. 2 Schematic of captive drop apparatus 
concentration: $\alpha=\gamma m$, where $\mathrm{m}$ is molality. When a solute experience an ionic dissociation (formation of cation (c) and anion (a)) in a solvent, its mean activity and activity coefficient can be calculated from Eq. 7. In this equation, $\mathrm{P}$ can be chemical activity or activity coefficient and $\vartheta_{a}$ and $\vartheta_{c}$ are stoichiometric coefficients of ionization equation (Atkins and de Paula Atkins' 2002).

$P^{\left(\vartheta_{a}+\vartheta_{c}\right)}=P_{a}^{\vartheta_{a}} P_{c}^{\vartheta_{c}}$

Because activity coefficient depends on ionic strength (I: see Eq. 8) and properties of dissociated ions, several models, such as Debye-Hückel equation, extended Debye-Hückel equation, Davies equation and Pitzer model were developed to predict activity coefficient of ionic solutions.

$I=\frac{1}{2} \sum_{i} m_{i} Z_{i}^{2}$

where $Z_{i}$ is the charge of ion $i$ and $m_{i}$ is the molality of ion $i$.

The ionic strengths of brines in this work are in the range of (0.9-6). For such high values of ionic strength, it was preferred that Harvie's and Weare equation is used to predict activity coefficient of brines. This equation was based on the Pitzer model for aqueous ionic solutions. Equations of Harvie and Weare model are as follow (Kim and Frederick Jr 1988):

The parameters $B_{a c}$ and $B_{a c}^{\prime}$ explain the interaction of oppositely charged ions. These parameters are found using following equations:

$B_{a c}=\beta_{a c}^{(0)}+\beta_{a c}^{(1)} f\left(\alpha_{1} \sqrt{I}\right)$

$B_{a c}^{\prime}=\frac{\beta_{a c}^{(1)} f^{\prime}\left(\alpha_{1} \sqrt{I}\right)}{I}$

In Eqs. 10 and 11, $\alpha_{1}=2$. If $X=\alpha_{1} \sqrt{I}$, then $f\left(\alpha_{1} \sqrt{I}\right)$ and $f^{\prime}\left(\alpha_{1} \sqrt{I}\right)$ can be written as Eqs. 12 and 13:

$f(x)=\frac{2\left[1-(1+X) e^{-X}\right]}{X^{2}}$

$f^{\prime}(X)=-\frac{2\left[1-\left(1+X+0.5 X^{2}\right) e^{-X}\right]}{X^{2}}$

Finally, $C_{a c}$ is calculated from Eq. 14:

$C_{a c}=\frac{C_{a c}^{\phi}}{2 \sqrt{\left|Z_{a} Z_{c}\right|}}$

$\ln \left(\gamma_{a c}\right)=-\left|Z_{a} Z_{c}\right| A\left[\frac{\sqrt{I}}{1+b \sqrt{I}}+\frac{2}{b} \ln (1+b \sqrt{I})\right]+4 m\left(\frac{\vartheta_{a} \vartheta_{c}}{\vartheta}\right)\left(B_{a c}+\frac{I}{2} B_{a c}^{\prime}\right)+6 m^{2}\left(\frac{\vartheta_{a} \vartheta_{c}}{\vartheta}\right) \vartheta_{c} Z_{c} C_{a c}$

where $\gamma_{a c}$ is the activity coefficient, $\vartheta$ is summation of stoichiometric coefficients $\left(\vartheta_{a}+\vartheta_{c}\right)$ and constants $\mathrm{A}$ and $\mathrm{b}$ are 0.392 and 1.2 at $25^{\circ} \mathrm{C}$, respectively.
Kim and Frederick Jr (1988) calculated $\beta_{a c}^{(0)}, \beta_{a c}^{(1)}$ and $C_{a c}^{\phi}$ for different ionic solutions at $25{ }^{\circ} \mathrm{C}$. Values of these parameters for $\mathrm{NaCl}$ in water are $0.07722,0.25183$ and
Fig. 3 IFT between oil sample A and brines at different concentrations and pressures at $25{ }^{\circ} \mathrm{C}$

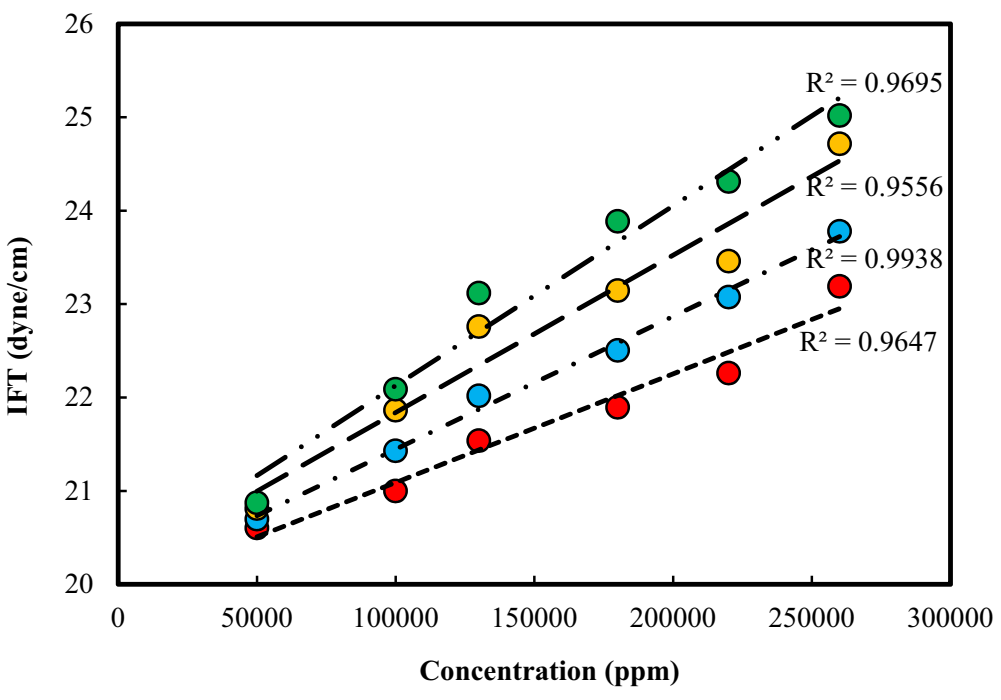

OPressure: 2500 psia OPressure: $3000 \mathrm{psia}$ OPressure: 3500 psia OPressure: 4000 psia 
Fig. 4 Interfacial tension versus pressure for different concentrations at $25^{\circ} \mathrm{C}$

Fig. $5 \Gamma \ln \alpha$ versus concentration at different pressures

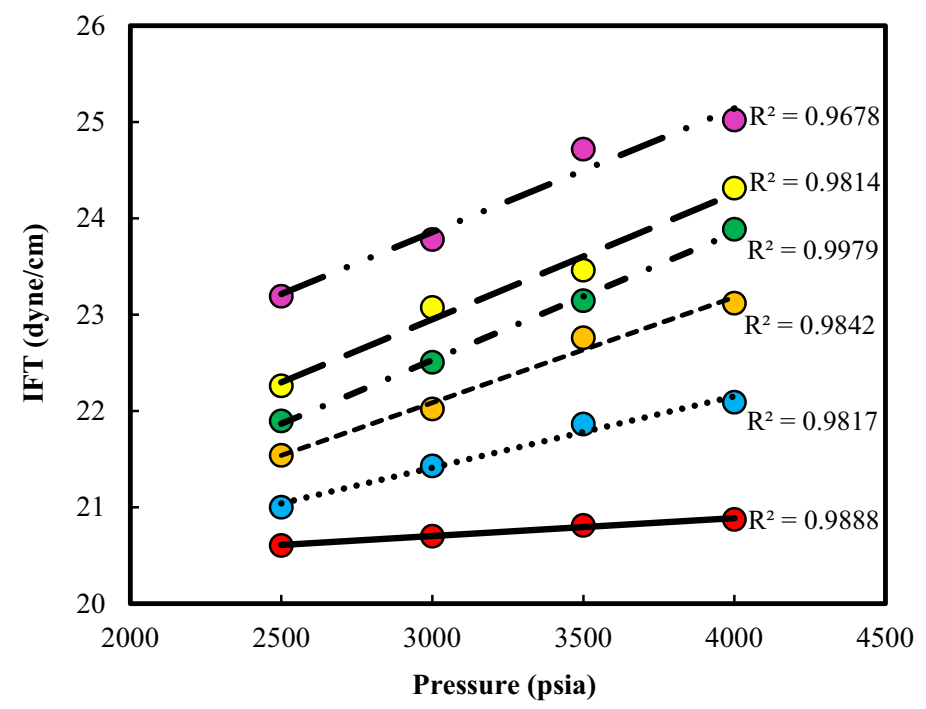

OConcentration:50000ppm

OConcentration: $100000 \mathrm{ppm}$ OConcentration: $130000 \mathrm{ppm}$ OConcentration: $180000 \mathrm{ppm}$ OConcentration:220000ppm OConcentration:260000ppm

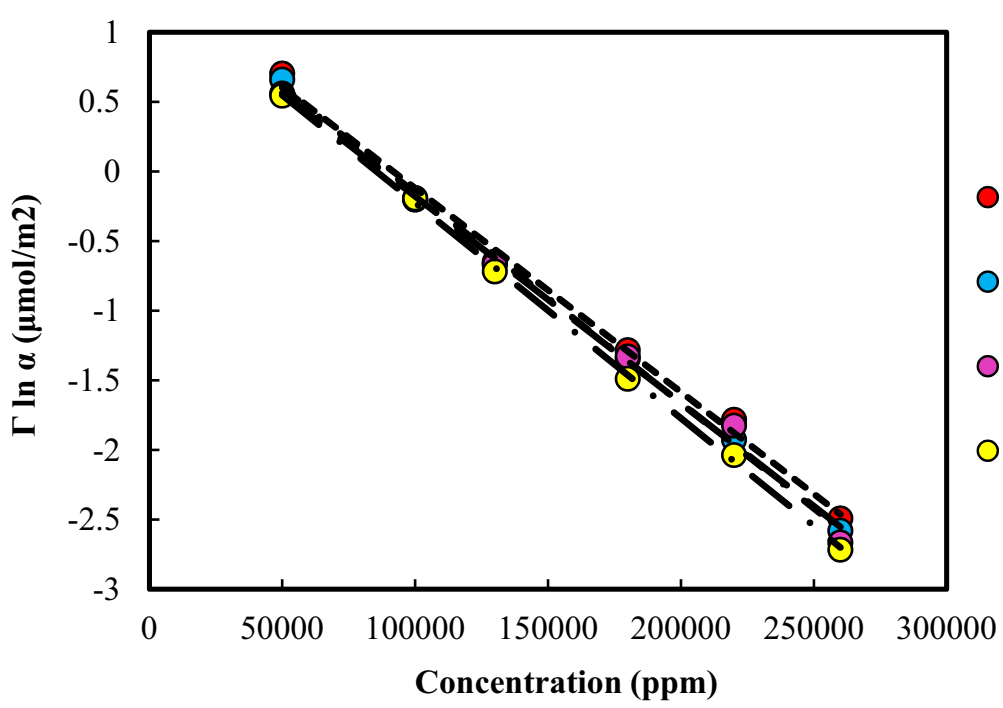

Pressure: 2500psia

OPressure: 3000 psia

OPressure: 3500psia

OPressure: 4000psia

Concentration (ppm)

0.00106 , respectively. Data related to calculation of surface excess concentration of $\mathrm{NaCl}$ at $25^{\circ} \mathrm{C}$ are given in Table 6.

To justify linear increasing trend of IFT versus concentration in Fig. 3, Eq. 5 is used. From Eq. 5 it can be inferred that variation of IFT with respect to concentration is proportional to change in $[\Gamma \ln \alpha]$ versus concentration. For this reason, $\Gamma \ln \alpha$ at $25^{\circ} \mathrm{C}$ and different pressures is plotted versus concentration in Fig. 5. It is clearly observed that the linear equations are fitted on data very well. Negative slopes of lines in Fig. 5 confirm increasing of interfacial tension versus concentration in a linear manner. $\mathrm{R}^{2}$ are $0.9951,0.9984,0.995$ and 0.993 from 2500 to 4000 psia.

Also, effect of pressure on IFT can be deduced from this figure. Figure 5 shows that IFT data for different pressures are very close to each other although their difference increases with increasing salinity. This figure confirms the insignificant changes of IFT between brines and crude oil with respect to pressure.

Table 6 Data related to calculation of surface excess concentration of $\mathrm{NaCl}$ at $25^{\circ} \mathrm{C}$

\begin{tabular}{llll}
\hline $\begin{array}{l}\text { Concentration } \\
(\mathrm{ppm})\end{array}$ & Ionic strength & $\begin{array}{l}\text { Activity coef- } \\
\text { ficient }\end{array}$ & Mean activity \\
\hline 50,000 & 0.9 & 0.73 & 0.66 \\
100,000 & 1.9 & 0.59 & 1.11 \\
130,000 & 2.55 & 0.54 & 1.37 \\
180,000 & 3.75 & 0.48 & 1.79 \\
220,000 & 4.82 & 0.44 & 2.14 \\
260,000 & 6 & 0.42 & 2.5 \\
\hline
\end{tabular}




\section{Asphaltene Effect on IFT of Four Oil Samples}

In mentioned works ("Effect of asphaltene on IFT between brines and oils' section), the investigators extracted resin and asphaltene and then examined their effects on IFT in the absence of other fractions of oil phase. We believe that all fractions play a role in this phenomenon. Hence, in this paper, the effect of natural surfactants of oil phase on IFT is investigated in the presence of all fractions of oil. Hydrocarbon phases are four live oil samples, namely samples A, B, C and D from four Iranian reservoirs. These live samples are prepared by recombination of separator gas and oil samples from production units. SARA separation test was performed on all samples. Results of SARA analysis are given in Table 3. IFT between these oil samples and brine $(180,000 \mathrm{ppm} \mathrm{NaCl}$ in distilled water) were measured using captive drop instrument at $25{ }^{\circ} \mathrm{C}$ and 3000 psia. Results of IFT measurement are given in Table 7.

If asphaltene content of four oil samples are considered as the only affecting parameter on IFT values, then according to the last column of Table 3, it is expected that the oil sample with higher portion of asphaltene would have lower IFT with respect to identical brines ( $<\mathrm{D}<\mathrm{C}<\mathrm{A}$ ). Results show a different trend $(B<A<C<D)$. Sample C has a higher asphaltene content compared with sample A, but it has a higher IFT. Why? The answer comes from the fact that all asphaltene particles are not free to go to the interface. In order to clarify this statement we use colloidal model. The colloidal model presumes that the asphaltenes are colloidal particles surrounded by adsorbed resins. The resins are assumed to partition between the asphaltene particles and the solvent. The more asphaltene surrounded by resins, the less freedom to act as a surfactant and reduce IFT. It means the more asphaltenes become unstable, the more freedom for asphaltenes to go to the interface and reduce IFT.

One of the most popular indices for predicting the asphaltene stability are the asphaltene-resin ratio (A/R). $\mathrm{A} / \mathrm{R}$ is the ratio of asphaltenes to resins fractions resulted from SARA test. Asomaning (2003) stated that for a given oil, the higher the A/R the more unstable the oil is. The ratio makes sense intuitively since the resins are one of the fractions that are known as peptizing agents of asphaltenes. Since the effects of saturates and aromatics are not included in this method, it may predict incorrectly the stability of asphaltenes in some crudes. Based on A/R ratios in Table 7, IFT values should be in this order: $\mathrm{D}<\mathrm{C}<\mathrm{B}<\mathrm{A}$, but experiment says that $\mathrm{B}<\mathrm{A}<\mathrm{C}<\mathrm{D}$. Therefore, $\mathrm{A} / \mathrm{R}$ is not an appropriate method to predict the effect of asphaltene on IFT reduction.

We have to use an index that includes the effects of all fractions of oil. The Colloidal Instability Index (CII) assumes the oil sample as a colloidal system made up of the fractions as saturates, aromatics, resins, and asphaltenes. The CII expresses the asphaltene stability in terms of these fractions and is defined as the mass ratio of the sum of asphaltenes and its flocculants (saturates) to the sum of its peptizers (resins and aromatics) in a crude oil. CII uses the weight percentages resulted from SARA test (see Table 7). The CII has been used to predict the asphaltene stability in crude oil-solvent mixtures (Asomaning and Watkinson 2000). The CII measures relative stability; the higher the value, the more unstable the asphaltenes in the oil are and consequently the more freedom the asphaltenes have to act as surfactant and reduce IFT. Indeed, the higher value of the CII parameter leads to the lower value of the IFT between brine and crude oil. Experimental results (see Table 6) confirmed this point and showed that CII parameter is an appropriate criterion for analyzing the effect of asphaltene on the IFT between brine and crude oil.

Two points should be kept in mind when using this method for analyzing asphaltene effect on IFT. The first one is that as Yarranton et al. (2000) showed, because of different structure of asphaltenes in different oils, the degree of being surface active may be different for various asphaltenes. Hence, when CII of two oil samples are close to each other, nature of asphaltenes determine which oil sample will have lower IFT. The other point is that asphaltene can lower the IFT up to a certain point. It means that as the oil sample becomes more unstable, the asphaltene particles get more freedom to go to the interface and reduce IFT. But when the sample reaches the asphaltene onset condition, asphaltene particles start to come out of solution and aggregate. At this point, asphaltene particles attract each other and get heavy.
Table 7 IFT, asphaltene/resin ratio and colloidal instability index of four oil samples

\begin{tabular}{lllll}
\hline Oil sample & A & B & C & D \\
\hline IFT (dyne/cm) & $22.51(\mathrm{SD}=0.01)$ & $20.85(\mathrm{SD}=0.02)$ & $25.52(\mathrm{SD}=0.02)$ & $\begin{array}{c}26.14 \\
(\mathrm{SD}=0.03)\end{array}$ \\
Asphaltene/resin & 0.11 & 0.36 & 0.63 & 1.04 \\
Colloidal instability index & 1.41 & 1.61 & 1.17 & 0.68 \\
\hline
\end{tabular}


Therefore, they cannot stay at the interface and will precipitate. Along with precipitation, asphaltene concentration at the interface will decrease and hence the IFT will increase.

One of the methods used for determination of asphaltene onset point is IFT measurement method (Mousavi-Dehghani et al. 2004). In this method, precipitant is added gradually to the oil sample and IFT of solution is measured. IFT is almost constant until asphaltene onset point is reached. At this point IFT starts to increase with increasing percentage of precipitant added to the solution. At first, IFT do not change with adding precipitant which may seem to be in contrary with what has been presented. In the previous paragraph, it has been said that as the oil sample becomes more unstable, asphaltene particles get more freedom to go to the interface and reduce IFT until asphaltene onset point is reached. Indeed, adding precipitant will cause the oil to become more unstable but the IFT does not change with increasing instability. The answer to this contradiction comes from attention to the change in oil composition. As precipitant is added to the oil sample, the solubility parameter of solution will decrease. Also the oil density will decrease. Both of these factors will increase IFT. At the same time, adding precipitant will cause the sample to become more unstable. So, more freedom of asphaltene particles will lower the IFT. Reduction in oil density and solubility parameter of solution tend to increase IFT while adding precipitant makes oil more unstable and decreases IFT. Hence, at the first (before onset point) as a result of this competition, the IFT does not change very much. After reaching asphaltene onset point, the IFT reduction factor will vanish. Hence, the IFT will increase rapidly.

\section{Conclusions}

The following conclusions are drawn.

1. Linear increasing behavior of IFT with respect to pressure is obviously seen in this work. Linear trends of $\Gamma \ln \alpha$ at $25{ }^{\circ} \mathrm{C}$ with respect to salt concentration and the negative slope confirm linear increasing trend of IFT versus salinity.
2. This work shows weak dependency of IFT on pressure. IFT data for different pressures are very close to each other although their difference increases with increasing pressure.

3. Neither asphaltene content nor $\mathrm{A} / \mathrm{R}$ are good indicator of asphaltene effect on IFT because the effect of asphaltene on IFT should be investigated in presence of all fractions of oil. So, CII which includes the effects of all fractions of oil was proposed as the best index.

4. As the oil sample becomes more unstable, the asphaltene particles get more freedom to go to the interface and reduce IFT. But when the sample reaches the asphaltene onset condition, asphaltene particles start to come out of solution and aggregate. At this point asphaltene particles attract each other and get heavy. So, they cannot stay at the interface and will precipitate. Along with precipitation, asphaltene concentration at the interface will decrease and hence the IFT will increase.

The authors declare that they have no known competing financial interests or personal relationships that could have appeared to influence the work reported in this paper.

Funding The authors received no specific funding for this work.

Open Access This article is licensed under a Creative Commons Attribution 4.0 International License, which permits use, sharing, adaptation, distribution and reproduction in any medium or format, as long as you give appropriate credit to the original author(s) and the source, provide a link to the Creative Commons licence, and indicate if changes were made. The images or other third party material in this article are included in the article's Creative Commons licence, unless indicated otherwise in a credit line to the material. If material is not included in the article's Creative Commons licence and your intended use is not permitted by statutory regulation or exceeds the permitted use, you will need to obtain permission directly from the copyright holder. To view a copy of this licence, visit http://creativecommons.org/licenses/by/4.0/.

\section{Appendix}

Data related to Figs. 3 and 4 are given in Table 8 . 
Table 8 Data related to the IFT measurement of Figs. 3 and 4

\begin{tabular}{|c|c|c|c|c|c|c|c|c|c|c|c|c|}
\hline \multirow[t]{3}{*}{$P($ psia $)$} & \multicolumn{12}{|c|}{ Salinity (ppm) } \\
\hline & \multicolumn{2}{|l|}{50,000} & \multicolumn{2}{|c|}{100,000} & \multicolumn{2}{|c|}{130,000} & \multicolumn{2}{|c|}{180,000} & \multicolumn{2}{|c|}{220,000} & \multicolumn{2}{|c|}{260,000} \\
\hline & IFT & SD & IFT & $\mathrm{SD}$ & IFT & SD & IFT & SD & IFT & $\mathrm{SD}$ & IFT & $\mathrm{SD}$ \\
\hline 2500 & 20.60 & 0.02 & 21.00 & 0.03 & 21.54 & 0.04 & 21.89 & 0.01 & 22.26 & 0.03 & 23.19 & 0.01 \\
\hline 3000 & 20.70 & 0.01 & 21.43 & 0.01 & 22.02 & 0.05 & 22.51 & 0.02 & 23.08 & 0.04 & 23.78 & 0.01 \\
\hline 3500 & 20.81 & 0.03 & 21.87 & 0.02 & 22.76 & 0.02 & 23.15 & 0.02 & 23.46 & 0.04 & 24.72 & 0.03 \\
\hline 4000 & 20.88 & 0.03 & 22.09 & 0.05 & 23.12 & 0.02 & 23.89 & 0.03 & 24.31 & 0.02 & 25.02 & 0.04 \\
\hline 4500 & 20.94 & 0.02 & 22.91 & 0.01 & 24.12 & 0.06 & 24.57 & 0.05 & 24.93 & 0.01 & 25.40 & 0.03 \\
\hline
\end{tabular}

\section{References}

Acevedo S et al (2005) Asphaltenes and other natural surfactants from Cerro Negro crude oil. Stepwise adsorption at the water/toluene interface: film formation and hydrophobic effects. Energy Fuels 19(5):1948-1953

Alotaibi M, Nasr-El-Din H (2009) Effect of brine salinity on reservoir fluids interfacial tension. Paper SPE 121569

Alves DR et al (2014) Influence of the salinity on the interfacial properties of a Brazilian crude oil-brine systems. Fuel 118:21-26

Arya A et al (2015) Determination of asphaltene onset conditions using the cubic plus association equation of state. Fluid Phase Equilib 400:8-19

Ashoori S (2005) Mechanisms of asphaltene deposition in porous media. University of Surrey, London

Asomaning S (2003) Test methods for determining asphaltene stability in crude oils. Pet Sci Technol 21(3-4):581-590

Asomaning S, Watkinson A (2000) Petroleum stability and heteroatom species effects in fouling of heat exchangers by asphaltenes. Heat Transfer Eng 21(3):10-16

Atkins P, de Paula Atkins' J (2002) Physical chemistry. Oxford University Press, Oxford

Aveyard R, Saleem SM (1976) Interfacial tensions at alkane-aqueous electrolyte interfaces. J Chem Soc Faraday Trans 1: Phys Chem Condensed Phases 72:1609-1617

Badakshan A, Bakes P (1990) The influence of temperature and surfactant concentration on interfacial tension of saline water and hydrocarbon systems in relation to enhanced oil recovery by chemical flooding. Society of Petroleum Enginerring, SPE 20295MS, SPE

Bai JM et al (2010) Influence of interaction between heavy oil components and petroleum sulfonate on the oil-water interfacial tension. J Dispersion Sci Technol 31(4):551-556

Barati-Harooni A et al (2016) Experimental and modeling studies on the effects of temperature, pressure and brine salinity on interfacial tension in live oil-brine systems. J Mol Liq 219:985-993

Bonfillon A et al (1994) Dynamic surface tension of ionic surfactant solutions. J Colloid Interface Sci 168(2):497-504

Buckley JS, Fan T (2007) Crude oil/brine interfacial tensions1. Petrophysics 48(03):175-185

Cai B et al (1996) Interfacial tension of hydrocarbon + water/brine systems under high pressure. J Chem Eng Data 41(3):493-496

Castillo J et al (2009) Measurement of the refractive index of crude oil and asphaltene solutions: onset flocculation determination. Energy Fuels 24(1):492-495

Cratin PD (1993) Mathematical modeling of some pH-dependent surface and interfacial properties of stearic acid. J Dispersion Sci Technol 14(5):559-602

Da Silva Ramos AC et al (2001) Interfacial and colloidal behavior of asphaltenes obtained from Brazilian crude oils. J Petrol Sci Eng 32(2):201-216
Dandekar AY (2013) Petroleum reservoir rock and fluid properties. CRC Press, Boca Raton

Drexler $\mathrm{S}$ et al (2020) Effect of $\mathrm{CO}_{2}$ on the dynamic and equilibrium interfacial tension between crude oil and formation brine for a deepwater Pre-salt field. J Petrol Sci Eng 190:107095

Escobedo J, Mansoori GA (1995) Viscometric determination of the onset of asphaltene flocculation: a novel method. SPE Prod Facil 10(02):115-118

Flock D et al (1986) The effect of temperature on the interfacial tension of heavy crude oils using the pendent drop apparatus. J Cana Petrol Technol 25(02):72-77

Hammami A et al (2000) Asphaltene precipitation from live oils: an experimental investigation of onset conditions and reversibility. Energy Fuels 14(1):14-18

Hamouda AA, Karoussi O (2008) Effect of temperature, wettability and relative permeability on oil recovery from oil-wet chalk. Energies 1(1): 19-34

Hjelmeland O, Larrondo L (1986) Experimental investigation of the effects of temperature, pressure, and crude oil composition on interfacial properties. SPE Reserv Eng 1(04):321-328

Hoeiland S et al (2001) The effect of crude oil acid fractions on wettability as studied by interfacial tension and contact angles. J Petrol Sci Eng 30(2):91-103

Kashefi K et al (2016) Measurement and modelling of interfacial tension in methane/water and methane/brine systems at reservoir conditions. Fluid Phase Equilib 409:301-311

Keleşoğlu S et al (2011) Effect of aqueous phase pH on the dynamic interfacial tension of acidic crude oils and myristic acid in dodecane. J Dispersion Sci Technol 32(11):1682-1691

Kim HT, Frederick WJ Jr (1988) Evaluation of Pitzer ion interaction parameters of aqueous electrolytes at 25 . degree. C. 1 . Single salt parameters. J Chem Eng Data 33(2):177-184

Kord S, Ayatollahi S (2012) Asphaltene precipitation in live crude oil during natural depletion: experimental investigation and modeling. Fluid Phase Equilib 336:63-70

Kumar B (2012) Effect of salinity on the interfacial tension of model and crude oil systems. University of Calgary, Calgary

Lashkarbolooki M, Ayatollahi S (2016) Effect of asphaltene and resin on interfacial tension of acidic crude oil/sulfate aqueous solution: experimental study. Fluid Phase Equilib 414:149-155

Lashkarbolooki M, Ayatollahi S (2018) The effects of pH, acidity, asphaltene and resin fraction on crude oil/water interfacial tension. J Petrol Sci Eng 162:341-347

Lashkarbolooki M et al (2014) Effect of salinity, resin, and asphaltene on the surface properties of acidic crude oil/smart water/rock system. Energy Fuels 28(11):6820-6829

Lashkarbolooki M et al (2016) Synergy effects of ions, resin, and asphaltene on interfacial tension of acidic crude oil and low-high salinity brines. Fuel 165:75-85

$\mathrm{Li}, \mathrm{X}$. (2013). "Interfacial properties of reservoir fluids and rocks."

McCain WD (1990) The properties of petroleum fluids. PennWell Books, Tulsa 
Meybodi MK et al (2016) Determination of hydrocarbon-water interfacial tension using a new empirical correlation. Fluid Phase Equilib 415:42-50

Moeini F et al (2014) Toward mechanistic understanding of heavy crude oil/brine interfacial tension: the roles of salinity, temperature and pressure. Fluid Phase Equilib 375:191-200

Mousavi-Dehghani S et al (2004) An analysis of methods for determination of onsets of asphaltene phase separations. J Petrol Sci Eng 42(2):145-156

Najafi-Marghmaleki A et al (2016) Experimental investigation of effect of temperature and pressure on contact angle of four Iranian carbonate oil reservoirs. J Petrol Sci Eng 142:77-84

Okasha TM, Alshiwaish A (2009). Effect of brine salinity on interfacial tension in Arab-D carbonate reservoir, Saudi Arabia. In: SPE Middle East oil and gas show and conference, society of petroleum engineers

Sayed AM et al (2019) The effect of organic acids and salinity on the interfacial tension of n-decane/water systems. J Petrol Sci Eng 173:1047-1052

Serrano-Saldaña E et al (2004) Wettability of solid/brine/n-dodecane systems: experimental study of the effects of ionic strength and surfactant concentration. Colloids Surf A 241(1):343-349
Vijapurapu CS, Rao DN (2004) Compositional effects of fluids on spreading, adhesion and wettability in porous media. Colloids Surf A 241(1):335-342

$\mathrm{Xu} \mathrm{W}$ et al (2005) Measurement of surfactant-induced interfacial interactions at reservoir conditions. In: SPE annual technical conference and exhibition, society of petroleum engineers

Yarranton HW et al (2000) Investigation of asphaltene association with vapor pressure osmometry and interfacial tension measurements. Ind Eng Chem Res 39(8):2916-2924

Yen A et al (2001) Evaluating asphaltene inhibitors: laboratory tests and field studies. In: SPE international symposium on oilfield chemistry, society of petroleum engineers

Zaki $\mathrm{N}$ et al (2000) Effect of asphaltene and resins on the stability of water-in-waxy oil emulsions. Pet Sci Technol 18(7-8):945-963

Publisher's Note Springer Nature remains neutral with regard to jurisdictional claims in published maps and institutional affiliations. 